\title{
GMR
}

\section{Temporal and spatial expression profiles of Frizzled 3 in the ovary during the estrous cycle}

\author{
S.B. Wang ${ }^{1,2,3}$, Y.P. Liu' ${ }^{1,2}$, Z.H. Zhang ${ }^{2}$, Z.K. Wang ${ }^{2,3}$, Y.X. Xu ${ }^{3}$ and Z.C. Wang ${ }^{1,2,3}$ \\ ${ }^{1}$ Laboratory of Sport Physiology and Biomedicine, \\ School of Physical Education and Sport Sciences, Fujian Normal University, \\ Fuzhou, China \\ ${ }^{2}$ Provincial Key Laboratory for Developmental Biology and Neurosciences, \\ College of Life Sciences, Fujian Normal University, Fuzhou, China \\ ${ }^{3}$ College of Animal Science and Technology, Nanjing Agricultural University, \\ Nanjing, China \\ Corresponding authors: Z.C. Wang / Y.X. Xu \\ E-mail: zcwang@fjnu.edu.cn / xuyinxue@njau.edu.cn \\ Genet. Mol. Res. 15 (1): gmr.15017152 \\ Received August 7, 2015 \\ Accepted October 28, 2015 \\ Published January 8, 2016 \\ DOI http://dx.doi.org/10.4238/gmr.15017152
}

\begin{abstract}
Frizzled 3 is an important receptor in the $\mathrm{Wnt} / \mathrm{\beta}$-catenin pathway, a conserved signaling pathway that regulates gene expression and controls diverse developmental processes. However, the role of this protein during follicular development in the adult ovary is not known. The present study was designed to investigate the expression and localization of Frizzled 3 mRNA and protein during the estrous cycle in the mouse ovary through in situ hybridization (ISH), real-time quantitative polymerase chain reaction, immunohistochemistry and western blot. ISH results showed that in proestrus, high expression of Frizzled 3 was found in the granulosa and stroma with weak levels in the corpus luteum. In estrus and diestrus, the stroma had high Frizzled 3 expression, but levels were low in granulosa cells and corpus luteum. In the metestrus, moderate expression of Frizzled 3 was found in the stroma but low to no expression was found in luteal cells and follicles. The mRNA and protein levels of Frizzled 3 were found to be the highest in proestrus and diestrus compared to estrus and metestrus
\end{abstract}


$(\mathrm{P}<0.05)$, confirming the ISH results. During estrus and diestrus, high Frizzled 3 expression was observed in the stroma and moderate levels in granulosa cells, and during estrus and proestrus, low expression was seen in the oocyte cell membrane. The western blot results further confirmed this change during the estrous cycle. Together, these results indicate that Frizzled 3 is involved in regulating follicular development and oocyte maturation during the estrous cycle.

Key words: Frizzled 3; Estrous cycle; Ovary; Mouse

\section{INTRODUCTION}

During the mammalian reproductive cycle, the ovary undergoes extensive morphological and functional changes, which are related to many intricate cellular processes such as cell proliferation/differentiation, angiogenesis and apoptosis (Lipner and Maxwell, 1960; Lipner et al., 1974; Zhang et al., 2011a,b, 2015; Wang et al., 2012, 2015). These processes are mainly regulated by the pituitary gonadotropins follicle-stimulating hormone and luteinizing hormone (Richards, 1994), and are subject to many important ovarian-derived factors, such as the Wnt signaling pathways. In mammals, Wnt proteins can bind to Frizzled proteins, thereby activating different downstream pathways for regulating their physiological functions in vivo (MacDonald et al., 2007; Semenov et al., 2007; Schulte, 2010; Dijksterhuis et al., 2014).

Recently, Wnt signaling has been implicated in ovarian development, oogenesis, and early embryonic development (Chan et al., 1992; Vainio et al., 1999; Ricken et al., 2002; Boerboom et al., 2005; Hsieh et al., 2002, 2005; Kimura et al., 2006; Wu et al., 2007; Wang et al., 2009, 2010b; Lapointe et al., 2012). Vainio et al. (1999) found that Wnt 4-deficient mice exhibit sex reversal and a paucity of oocytes in the newborn ovary, while mice null for Frizzled 4 are infertile and exhibit impaired function of the corpus luteum (Hsieh et al., 2005). Wnt 2 and Frizzled 1 are expressed in the granulosa cells, while Wnt 4 and Frizzled 4 are expressed in the corpus luteum (Hsieh et al., 2002; Ricken et al., 2002). It has been reported that misregulation of Wnt/ $\beta$ catenin signaling in granulosa cells can contribute to granulosa cell tumor development, and defects in the Wnt/ $\beta$-catenin pathway often lead to human ovarian endometrioid adenocarcinoma (Boerboom et al., 2005; Wu et al., 2007). Expression of the stable, active form of $\beta$-catenin in primordial germ cell promoter tissue-nonspecific alkaline phosphatase (TNAP)-Cre-expressing cells and cell lineages results in male and female germ cell deficiency in mice (Kimura et al., 2006). Moreover, Frizzled 2 mRNA has been detected in a high steady state level in the rat ovary by northern analysis (Chan et al., 1992). The Frizzled 2 protein was highly expressed in granulosa cells and the membrane of oocytes during the mouse estrous cycle (Wang et al., 2010 b). Frizzled 1 is required for normal female fertility and may act in part to regulate oocyte maturation and cumulus cell function, but it is unlikely to function as the sole ovarian Wnt 4 receptor (Wang et al., 2009).

Co-immunoprecipitation experiments have shown that Wnt 2 can interact with Frizzled 3 in human cumulus cells (Lapointe et al., 2012) but very little is known about the expression pattern or function of Frizzled 3 in the mouse ovary. Therefore, the aim of this study was to explore the spatial and temporal expression profiles of Frizzled 3 mRNA and protein in the mouse ovary during the estrous cycle. 


\section{MATERIAL AND METHODS}

\section{Animals}

Female 5-week-old ICR mice were obtained from the Center of Laboratory Animals, Nantong University (China) and were housed under optimal conditions of hygiene, temperature, and humidity with 12-h intervals of light and dark. Commercial chow and tap water were continually available. All experimental procedures were performed under protocols approved by the Committee on the Care and Use of Animals in Research of Nanjing Agricultural University (China) and Fujian Normal University (China).

\section{Experimental design}

Adult female mice were divided (four per group) in proestrus $(P)$, estrus (E), metestrus (M), and diestrus (DI) groups by vaginal smear according to two consecutive estrous cycles (Wang et al., 2010b). Animals were then sacrificed by cervical dislocation. The uteruses from different groups were weighed and histone H3.2 mRNA levels were detected to validate estrous cycle classification. Ovaries from different groups were removed and used for extraction of RNA and protein or fixed for in situ hybridization (ISH) and immunohistochemistry (IHC) analyses.

\section{Quantitative polymerase chain reaction (qPCR)}

Real-time qPCR analysis was performed to analyze Frizzled 3 mRNA levels as previously described (Wang et al., 2010b). Both optimal annealing temperature and the amplification size of products are shown in Table 1. Frizzled 3 mRNA levels were normalized to 60S ribosomal (L-19) gene expression.

\begin{tabular}{|c|c|c|c|c|}
\hline Gene & GenBank accession No. & Primer sequence $\left(5^{\prime}-3^{\prime}\right)$ & Product size (bp) & Annealing temperature $\left({ }^{\circ} \mathrm{C}\right)$ \\
\hline \multirow[t]{2}{*}{ Frizzled 3} & NM_021458 & F: 5'-GGGAGTGTCCACAGCAAAGTGA-3' & 180 & 67.7 \\
\hline & & R: 5'-GTGTCGGGACTGCTCGTTGA-3' & & \\
\hline L-19 & NM_009078 & $\begin{array}{l}\text { F: 5'-ATGAGTATGCTCAGGCTACAGA-3' } \\
\text { R: 5'-GCATTGGCGATTTCATTGGTC-3' }\end{array}$ & 104 & 63.2 \\
\hline
\end{tabular}

$\mathrm{F}=$ forward primer; $\mathrm{R}=$ reverse primer.

\section{ISH}

The ISH procedure was performed as previously described (Wang et al., 2010b). Frizzled 3 RNA localization was determined using a commercial assay kit (Haoyang Inc., Tianjin, China) according to the manufacturer instructions. Frizzled 3 probes are shown in Table 2.

\begin{tabular}{|c|c|c|c|}
\hline Gene & GenBank accession No. & Probe sequence & Size (bp) \\
\hline \multirow[t]{5}{*}{ Frizzled 3} & NM_021458 & Antisense probes & \\
\hline & & 5'-TTACCCACCATACACTGCCAGCCATAG-3' & 27 \\
\hline & & 5'-GAGAGAAACCCCAACTACCACATACAGG-3' & 28 \\
\hline & & Sense probe & \\
\hline & & 5'-CTATGGCTGGCAGTGTATGGTGGGTAA-3' & 27 \\
\hline
\end{tabular}




\section{IHC}

The procedure for IHC was performed as previously described (Wang et al., 2010b). The Power-Vision ${ }^{\mathrm{TM}}$-PV 6001 kit (Haoyang Inc.) and 3,3'-diaminobenzidine (Haoyang Inc.) were used. The slides were incubated in rabbit polyclonal Frizzled 3 antibody (F3179, 1:300 dilution; Sigma, St.-Louis, MO, USA). The results of IHC and ISH were recorded with a DS-5Mc digital camera system (Nikon, Kanagawa, Japan), and the digital images were processed by NIS-Elements Basic Research (version 2.30; Nikon).

\section{Western blot}

The western blot procedure was performed as previously described (Wang et al., 2010b). Following transfer, the membranes were incubated with rabbit polyclonal Frizzled 3 antibodies (ab75233, 1:1000 dilution; Abcam, Cambridge, MA, USA). Anti-glyceraldehyde-3-phosphate dehydrogenase (GAPDH) antibody (1:10,000 dilution; Chemicon International, Temecula, CA, USA) was used as the protein loading control. Membranes were detected with $\mathrm{ECL}^{\mathrm{TM}}$ western blotting detection reagent (Amersham Biosciences, Little Chalfont, Buckinghamshire, England). The relative intensity of Frizzled 3 compared to GAPDH was quantified using the Quantity One software (Bio-Rad Laboratories, Hercules, CA, USA).

\section{Statistical analysis}

The statistical analysis of data from real-time $\mathrm{qPCR}$ and western blot were assessed by one-way ANOVA (SPSS for Windows package release 13.0; SPSS Inc., Chicago, IL, USA). P < 0.05 was considered to be statistically significant.

\section{RESULTS}

\section{Follicular development model in the ovary of adult mice}

To clarify the temporal and spatial expression profiles of Frizzled 3 in the ovary during the estrous cycle, we used the follicular development model in the ovary of adult female mice. Stage of estrous cycle was confirmed by vaginal smear (Figure 1) and ovarian histology (Figure 2).

\section{Localization of Frizzled 3 mRNA in the mouse ovary during the estrous cycle}

To understand the role of Frizzled 3 in the ovary, ISH assays for Frizzled 3 mRNA were performed to identify the localization of Frizzled 3 in the ovary during follicular development. Our results found strong expression of Frizzled 3 mRNA in the stroma and granulosa cells in the follicles during all estrous stages, but weak expression in the corpus luteum at the P stage (Figure 3A). The staining of Frizzled 3 mRNA was high in the stroma but low to undetectable in the granulosa cells and corpus luteum at the E stage (Figure 3B). Further analysis found that Frizzled 3 mRNA was moderately expressed in the stroma and weakly expressed in the corpus luteum at the $M$ stage (Figure $3 \mathrm{C}$ ), while high levels of expression were seen in the stroma and low expression in the granulosa cells and corpus luteum at the DI stage (Figure 3D). Control sections without probe or 
with sense probe only did not show any specific signals (Figure 3E). All Frizzled 3 probes yielded similar patterns of expression. These findings indicate that the strongest hybridization signal was observed at the $\mathrm{P}$ and DI stages followed by the $\mathrm{E}$ and $\mathrm{M}$ stages.
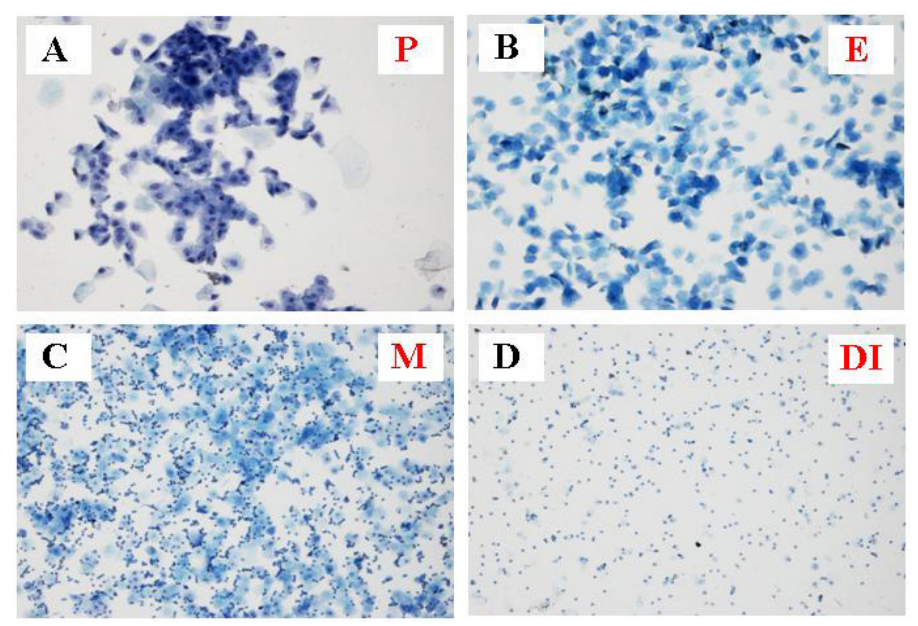

Figure 1. Images of the vaginal smear for the identification of the estrous cycle in mice. The vaginal smear was performed and examined for the identification of the estrous cycle. A. Indicates the proestrus stage (P); B. Indicates the estrus stage (E); C. Indicates the metestrus stage (M); and D. Indicates the diestrus stage (DI).
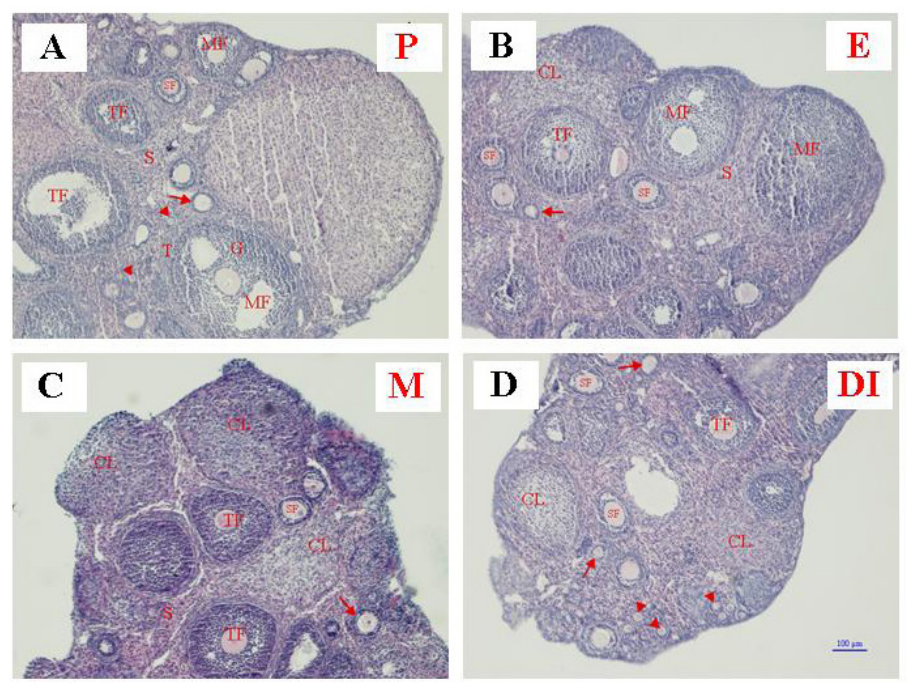

Figure 2. Ovarian histology at the different stages of the estrous cycle. Ovarian histology was further examined for the identification of the estrous cycle according to follicular development. A. Indicates the proestrus stage (P); $B$. Indicates the estrus stage (E); C. Indicates the metestrus stage (M); and D. Indicates the diestrus stage (DI). pr = primary follicle; $\mathrm{sf}=$ secondary follicle; $\mathrm{po}=$ preovulatory follicle; ov = ovulatory follicle; o = oocyte; $\mathrm{GC}=$ granulosa cell; $\mathrm{T}=$ theca; $\mathrm{S}$ = stroma; $\mathrm{CL}=$ corpus luteum. $\mathrm{Bar}=100 \mu \mathrm{m}$. 


\section{Frizzled 3 mRNA levels in the mouse ovary during the estrous cycle}

Real-time qPCR was used to examine the mRNA levels of Frizzled 3 at different stages of the estrous cycle. Our results demonstrated higher mRNA levels of Frizzled 3 at the $P$ and DI stages ( $P<0.05$; Figure 4) compared to the $E$ and $M$ stages (Figure 4), which is consistent with the results of ISH (Figure 3).
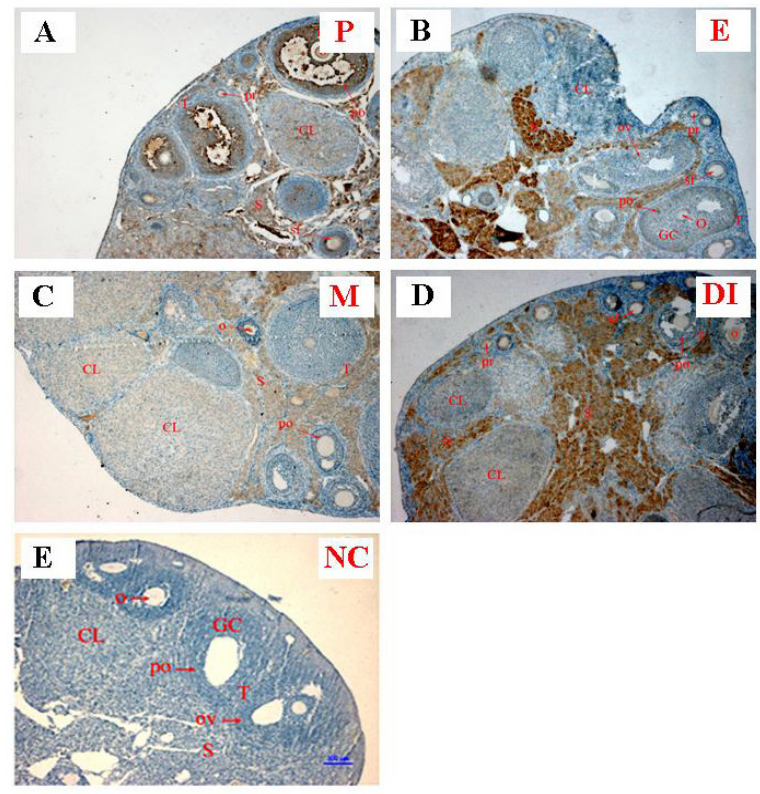

Figure 3. Expression level and localization of Frizzled 3 mRNA in the ovary during the estrous cycle. In situ hybridization analysis of Frizzled 3 mRNA was performed to determine the expression level and localization of Frizzled 3 mRNA in the ovary at the different stages of the estrous cycle. A. Indicates the proestrus stage (P); B. Indicates the estrus stage (E); C. Indicates the metestrus stage (M); D. Indicates the diestrus stage (DI), and E. Indicates the negative control $(\mathrm{NC}) . \mathrm{pr}=$ primary follicle; $\mathrm{sf}=$ secondary follicle; $\mathrm{po}=$ preovulatory follicle; ov = ovulatory follicle; $\mathrm{o}=$ oocyte; $\mathrm{GC}=$ granulosa cell; $\mathrm{T}=$ theca; $\mathrm{S}=$ stroma; $\mathrm{CL}=$ corpus luteum. $\mathrm{Bar}=100 \mu \mathrm{m}$.

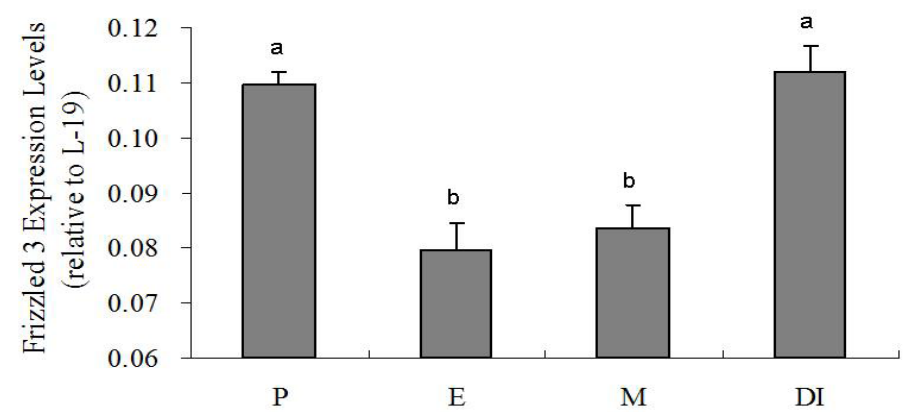

Figure 4. Frizzled 3 mRNA expression levels in the ovary during the estrous cycle. The levels of Frizzled 3 mRNA normalized to L-19 were detected by real-time qPCR in the ovary during the estrous cycle. Different letters $(a$ and $b)$ denote significance values $(P<0.05)$ by the Tukey test. $P=$ proestrus; $E=$ estrus; $M=$ metestrus; $D I=$ diestrus. 


\section{Localization of the Frizzled 3 protein in the mouse ovary during the estrous cycle}

IHC was performed to determine the expression and localization of the Frizzled 3 protein in the mouse ovary during the estrous cycle (Figure 5). In the ovary during the P stage, Frizzled 3 was visualized strongly in the stroma and granulosa cells but and a low signal was obtained in the oocyte membrane and corpus luteum (Figure 5A). During the $E$ stage, moderate expression of Frizzled 3 was found in the stroma and granulosa cells and weak expression of Frizzled 3 was found in the corpus luteum and membrane of the oocyte (Figure 5B). During the M stage, Frizzled 3 was weakly expressed in the stroma and membrane of the oocyte and no signal was found in granulosa cells (Figure $5 \mathrm{C}$ ). During the DI stage, a moderate Frizzled 3 signal was found in the granulosa cells while a weak signal was observed in the corpus luteum and stroma (Figure 5D). The control sections, which were incubated without primary antibody, did not produce any positive staining for Frizzled 3 (Figure 5E). The localization pattern of the Frizzled 3 protein was similar to Frizzled 3 mRNA during the estrous cycle. However, some differences were observed; according to IHC, Frizzled 3 protein expression was strongest in the granulosa cells while ISH results showed that Frizzled 3 mRNA levels were highest in the stroma. Together, these results indicate that Frizzled 3 may play an important role in the regulation of ovarian function.
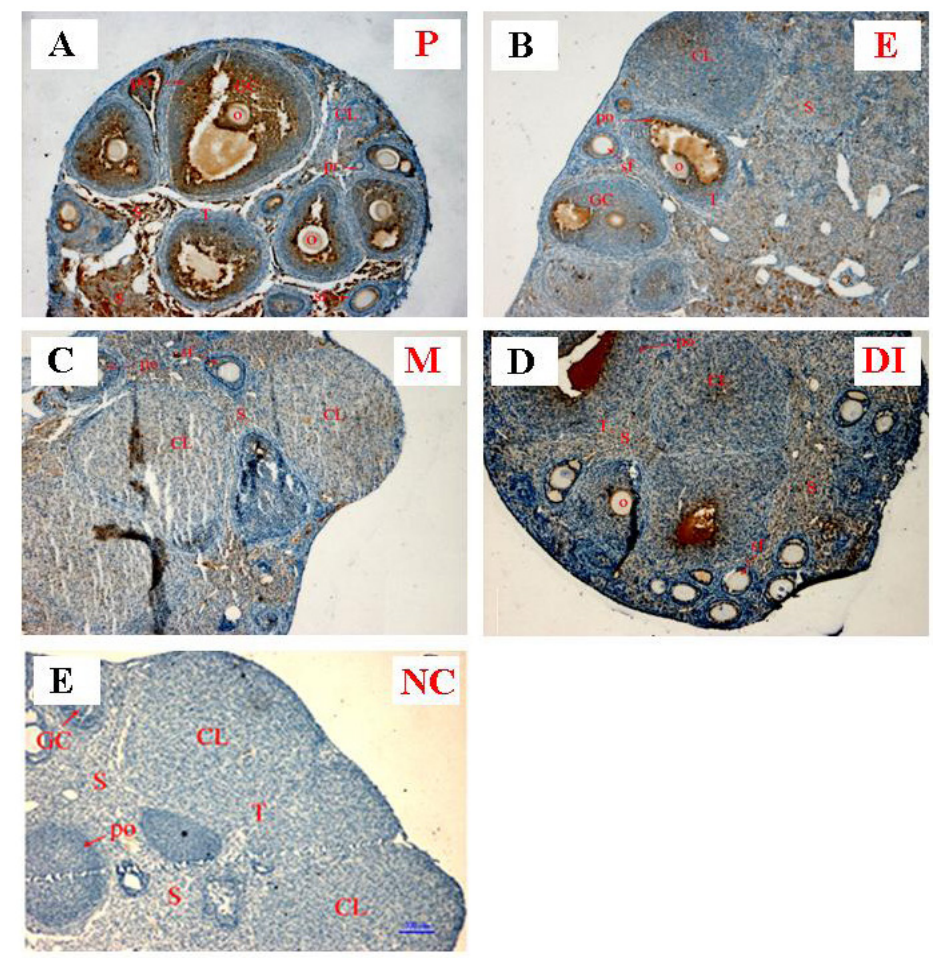

Figure 5. Expression and localization of the Frizzled 3 protein in the ovary at different stages of the estrous cycle. A. Indicates the proestrus stage (P); B. Indicates the estrus stage (E); C. Indicates the metestrus stage (M); D. Indicates the diestrus stage (DI); and $\mathrm{E}$. Indicates the negative control $(\mathrm{NC}) . \mathrm{pr}=$ primary follicle; $\mathrm{sf}=$ secondary follicle; $\mathrm{po}=$ preovulatory follicle; ov = ovulatory follicle; $\mathrm{o}=$ oocyte; $\mathrm{GC}=$ granulosa cell; $\mathrm{T}=$ theca; $\mathrm{S}=$ stroma; $\mathrm{CL}=$ corpus luteum. Bar $=100 \mu \mathrm{m}$. 


\section{Expression level of the Frizzled 3 protein in the mouse ovary during the estrous cycle}

To further confirm the IHC results, the expression of the Frizzled 3 protein was detected by western blot. The results showed that Frizzled 3 was expressed to a higher degree at the $P$ and $\mathrm{DI}$ stages compared to the $\mathrm{E}$ and $\mathrm{M}$ stages $(\mathrm{P}<0.05$; Figure 6$)$. These results show that Frizzled 3 may be involved in follicular development during the estrous cycle.

$\mathbf{A}$

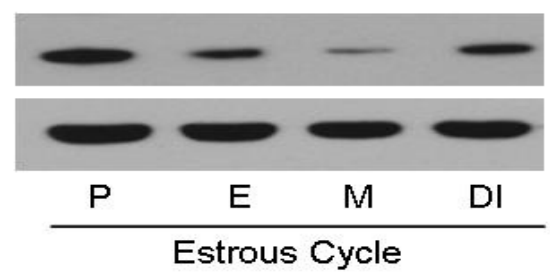

Frizzled 3

GAPDH

Estrous Cycle

\section{B}

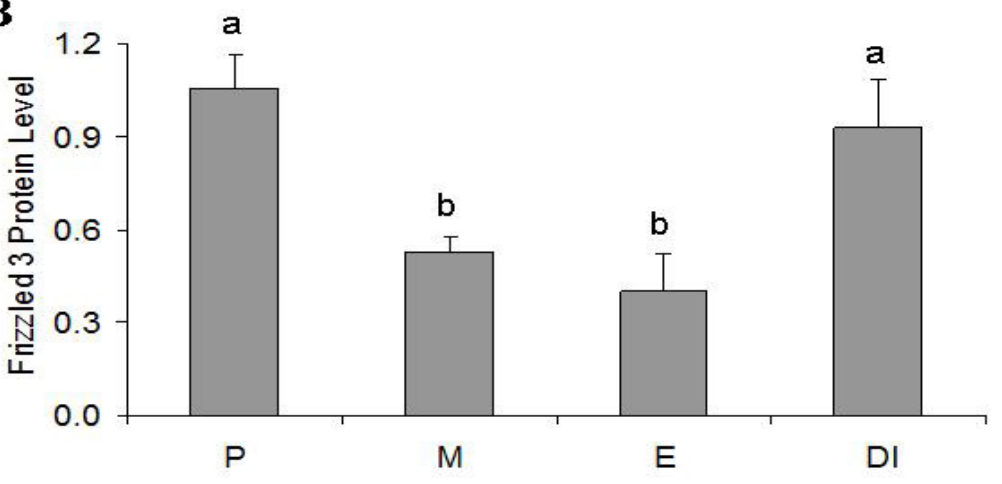

Figure 6. Frizzled 3 protein expression in the ovary during the estrous cycle. The level of the Frizzled 3 protein was detected by western blot in the ovary during the estrous cycle. A. Pepresentative western blot depicting the protein level of Frizzled 3 with $\beta$-actin as the loading control. B. Densitometric analysis of Frizzled 3 expression from the western blot normalized to the GAPDH control. Different letters $(a$ and $b)$ denote significant values $(P<0.05)$ by the Tukey test. $\mathrm{P}=$ proestrus; $\mathrm{E}=$ estrus; $\mathrm{M}=$ metestrus; $\mathrm{DI}=$ diestrus.

\section{DISCUSSION}

The Wnt/Frizzled signaling pathway orchestrates and influences a myriad of cell and developmental processes such as proliferation, differentiation, cell-fate decisions, migration, and embryonic development. Misregulation of Wnt signaling can lead to various diseases ranging from cancer and inflammatory diseases to metabolic and neurological disorders. Previous research showed that Wnt signaling is crucial for ovarian development, and various Wnt pathways are localized to different parts of the ovary (Vainio et al., 1999; Hsieh et al., 2002; Ricken et al., 2002). Abnormal Wnt signaling has been shown to result in ovarian tumors (Boerboom et al., 2005; Wu et al., 2007). Our results indicate that the Wnt signaling pathway is vital to regulating follicular development in the ovary. So far, studies have showed that Frizzled 1 and Frizzled 2 are found in different parts of the rodent ovary (Chan et al., 1992; Wang et al., 2010b; Lapointe et 
al., 2012). Interestingly, in human cumulus cells, Frizzled 3 can bind to Wnt 2, but it is not known which downstream signaling pathways are activated following this interaction (Wang et al., 2009). Furthermore, the Wnt 1/Frizzled 3 system plays a regulatory role in the achievement of the in vitro capacitation and subsequent in vitro acrosome exocytosis of porcine spermatozoa (Covarrubias et al., 2015). Therefore, it is important to examine the expression patterns of Frizzled 3 in the ovary during the estrous cycle.

In the present study, the spatial and temporal expression profiles of Frizzled 3 were examined in vivo in the ovary during the estrous cycle. Frizzled 3 mRNA and protein levels were significantly higher at the $P$ and $D I$ stages than at the $E$ and $M$ stages. These results imply that Frizzled 3 may be involved in the onset and termination of the estrous cycle and most likely plays a role in folliculogenesis and atrophy of the corpus luteum. Furthermore, using ISH, we showed that Frizzled 3 mRNA levels are higher in the ovary during the $\mathrm{P}$ and DI stages, where it is mainly localized in the stroma or granulosa cells. During the $E$ and M stages, Frizzled 3 mRNA was detected moderately in the stroma. The expression pattern of the Frizzled 3 protein was mostly consistent with its mRNA levels. A strong signal appeared in the stroma at the P and DI stages and few localization differences were observed. Frizzled 3 protein was expressed moderately in the granulosa cells at the $E$ and $D$ stages. These results indicate that some other factors may be involved in regulating the expression of Frizzled 3 at the translational level.

In the ovary, the follicles are embedded in the connective tissue (stroma). The central stroma (medulla) contains a rich vascular bed, lymphatic vessels, and nerves within loose connective tissue (Zhang et al., 2015). Currently, the function of the stroma in the ovary has been poorly understood. Studies have identified differential expression of inflammation-related genes in the ovarian stroma and granulosa cells of polycystic ovary syndrome (PCOS) patients, indicating that these are important regions for pathophysiological changes during PCOS (Schmidt et al., 2014). Our study found the strongest signals for Frizzled 3 in the stroma and granulosa cells during the estrous cycle. Therefore, we speculate that Frizzled 3 may be related to the pathogenesis of PCOS but this issue needs to be further investigated. In addition, recent evidence in the mouse ovary demonstrated that misregulation of $\mathrm{Wnt} / \mathrm{\beta}$-catenin signaling can result in granulosa cell tumors (Boerboom et al., 2005). Wnt 2/ß-catenin signaling contributes to regulating the proliferation of granulosa cells (Wang et al., 2010a). Meanwhile, immunofluorescence analysis of cultured granulosa cells revealed that it colocalizes with Frizzled 3 and Frizzled 9. Co-immunoprecipitation experiments showed that the Wnt 2 antibody could pull down Frizzled 3 and Frizzled 9, but only Frizzled 9 antibody could pull down Wnt 2, suggesting that Frizzled 9 may be the preferred receptor for Wnt 2 in mouse granulosa cells (Wang et al., 2010a). Interestingly, our study revealed the strongest signals (highest expression) for Frizzled 3 in the granulosa cells during the estrous cycle. However, the possible effect and mechanism of Frizzled 3 in granulosa cells need to be further explored.

In conclusion, our results clearly show that Frizzled 3 is highly expressed during the proestrus and diestrus stages; moreover, it is primarily localized in the granulosa cells and stroma. These findings indicate that Frizzled 3 may be involved in follicle growth, oocyte maturation, and luteal atresia during the estrous cycle.

\section{Conflicts of interest}

The authors declare no conflict of interest. 


\section{ACKNOWLEDGMENTS}

Research supported by the National Natural Science Foundation of China (\#31101032 and \#31271255), the Program for New Century Excellent Talents in University of Ministry of Education of China (\#NCET-120614), the Doctoral Foundation of the Ministry of Education in China (\#20113503120002), and the Fujian Provincial Science and Technology Projects of the Department of Education (\#JB14041).

\section{REFERENCES}

Boerboom D, Paquet M, Hsieh M, Liu J, et al. (2005). Misregulated Wnt/beta-catenin signaling leads to ovarian granulosa cell tumor development. Cancer Res. 65: 9206-9215. http://dx.doi.org/10.1158/0008-5472.CAN-05-1024

Chan SD, Karpf DB, Fowlkes ME, Hooks M, et al. (1992). Two homologs of the Drosophila polarity gene frizzled (fz) are widely expressed in mammalian tissues. J. Biol. Chem. 267: 25202-25207.

Covarrubias AA, Yeste M, Salazar E, Ramírez-Reveco A, et al. (2015). The Wnt1 ligand/Frizzled 3 receptor system plays a regulatory role in the achievement of the 'in vitro' capacitation and subsequent 'in vitro' acrosome exocytosis of porcine spermatozoa. Andrology 3: 357-367. http://dx.doi.org/10.1111/andr.12011

Dijksterhuis JP, Petersen J and Schulte G (2014). WNT/Frizzled signalling: receptor-ligand selectivity with focus on FZD-G protein signalling and its physiological relevance: IUPHAR Review 3. Br. J. Pharmacol. 171: 1195-1209. http://dx.doi.org/10.1111/bph.12364

Hsieh M, Johnson MA, Greenberg NM and Richards JS (2002). Regulated expression of Wnts and Frizzleds at specific stages of follicular development in the rodent ovary. Endocrinology 143: 898-908. http://dx.doi.org/10.1210/endo.143.3.8684

Hsieh M, Boerboom D, Shimada M, Lo Y, et al. (2005). Mice null for Frizzled4 (Fzd4-/-) are infertile and exhibit impaired corpora lutea formation and function. Biol. Reprod. 73: 1135-1146. http://dx.doi.org/10.1095/biolreprod.105.042739

Kimura T, Nakamura T, Murayama K, Umehara H, et al. (2006). The stabilization of beta-catenin leads to impaired primordial germ cell development via aberrant cell cycle progression. Dev. Biol. 300: 545-553. http://dx.doi.org/10.1016/j.ydbio.2006.06.038

Lapointe E, Boyer A, Rico C, Paquet M, et al. (2012). FZD1 regulates cumulus expansion genes and is required for normal female fertility in mice. Biol. Reprod. 87: 104. http://dx.doi.org/10.1095/biolreprod.112.102608

Lipner HJ and Maxwell BA (1960). Hypothesis concerning the role of follicular contractions in ovulation. Science 131: 17371738. http://dx.doi.org/10.1126/science.131.3415.1737

Lipner H, Hirsch MA, Moudgal NR, MacDonald GJ, et al. (1974). Ovulating-inducing activity of FSH in the rat. Endocrinology 94: 1351-1358. http://dx.doi.org/10.1210/endo-94-5-1351

MacDonald BT, Semenov MV and He X (2007). SnapShot: Wnt/beta-catenin signaling. Cell 131: $1204 . e 1$. http://dx.doi.org/10.1016/j.cell.2007.11.036

Richards JS (1994). Hormonal control of gene expression in the ovary. Endocr. Rev. 15: 725-751. http://dx.doi.org/10.1210/edrv-15-6-725

Ricken A, Lochhead P, Kontogiannea M and Farookhi R (2002). Wnt signaling in the ovary: identification and compartmentalized expression of wnt-2, wnt-2b, and frizzled-4 mRNAs. Endocrinology 143: 2741-2749. http://dx.doi.org/10.1210/endo.143.7.8908

Schmidt J, Weijdegård B, Mikkelsen AL, Lindenberg S, et al. (2014). Differential expression of inflammation-related genes in the ovarian stroma and granulosa cells of PCOS women. Mol. Hum. Reprod. 20: 49-58. http://dx.doi.org/10.1093/molehr/gat051

Schulte G (2010). International Union of Basic and Clinical Pharmacology. LXXX. The class Frizzled receptors. Pharmacol. Rev. 62: 632-667. http://dx.doi.org/10.1124/pr.110.002931

Semenov MV, Habas R, Macdonald BT and He X (2007). SnapShot: Noncanonical Wnt Signaling Pathways. Cell $131: 1378$. e1. http://dx.doi.org/10.1016/j.cell.2007.12.011

Vainio S, Heikkilä M, Kispert A, Chin N, et al. (1999). Female development in mammals is regulated by Wnt-4 signalling. Nature 397: 405-409. http://dx.doi.org/10.1038/17068

Wang F, Zhang Z, Wang Z, Xiao K, et al. (2015). Expression and clinical significance of the HIF-1a/ET-2 signaling pathway during the development and treatment of polycystic ovary syndrome. J. Mol. Histol. 46: 173-181. http://dx.doi.org/10.1007/s10735-015-9609-4

Wang HX, Tekpetey FR and Kidder GM (2009). Identification of WNT/beta-CATENIN signaling pathway components in human cumulus cells. Mol. Hum. Reprod. 15: 11-17. http://dx.doi.org/10.1093/molehr/gan070

Wang HX, Li TY and Kidder GM (2010a). WNT2 regulates DNA synthesis in mouse granulosa cells through beta-catenin. Biol. Reprod. 82: 865-875. http://dx.doi.org/10.1095/biolreprod.109.080903 
Wang SB, Xing BS, Yi L, Wang W, et al. (2010b). Expression of Frizzled 2 in the mouse ovary during oestrous cycle. J. Anim. Physiol. Anim. Nutr. (Berl.) 94: 437-445.

Wang Z, Zhang Z, Wu Y, Chen L, et al. (2012). Effects of echinomycin on endothelin-2 expression and ovulation in immature rats primed with gonadotropins. Exp. Mol. Med. 44: 615-621. http://dx.doi.org/10.3858/emm.2012.44.10.070

Wu R, Hendrix-Lucas N, Kuick R, Zhai Y, et al. (2007). Mouse model of human ovarian endometrioid adenocarcinoma based on somatic defects in the Wnt/beta-catenin and PI3K/Pten signaling pathways. Cancer Cell 11: 321-333. http://dx.doi.org/10.1016/j.ccr.2007.02.016

Zhang Z, Yin D and Wang Z (2011a). Contribution of hypoxia-inducible factor-1 $\alpha$ to transcriptional regulation of vascular endothelial growth factor in bovine developing luteal cells. Anim. Sci. J. 82: 244-250. http://dx.doi.org/10.1111/j.1740-0929.2010.00832.x

Zhang Z, Yu D, Yin D and Wang Z (2011b). Activation of PI3K/mTOR signaling pathway contributes to induction of vascular endothelial growth factor by hCG in bovine developing luteal cells. Anim. Reprod. Sci. 125: 42-48. http://dx.doi.org/10.1016/j.anireprosci.2011.03.002

Zhang ZH, Chen LY, Wang F, Wu YQ, et al. (2015). Expression of hypoxia-inducible factor-1a during ovarian follicular growth and development in Sprague-Dawley rats. Genet. Mol. Res. 14: 5896-5909. http://dx.doi.org/10.4238/2015.June.1.7 